\title{
World Journal of Emergency

\section{Synchronous multiple small bowel intussusceptions in an adult with blue rubber bleb naevus syndrome: Report of a case and review of literature}

\author{
Clement Lee $^{1}$, Debasish Debnath*1, Tara Whitburn ${ }^{1}$, Mark Farrugia ${ }^{2}$ and \\ Federico Gonzalez ${ }^{1}$
}

\begin{abstract}
Address: ${ }^{1}$ Department of Surgery, Newham University Hospital, Plaistow, London, E13 8SL, UK and ${ }^{2}$ Department of Radiology, Newham University Hospital, Plaistow, London, E13 8SL, UK

Email: Clement Lee - workpecker@aol.com; Debasish Debnath* - d.debnath@mail.com; Tara Whitburn - t_whitburn@hotmail.com; Mark Farrugia - Mark.Farrugia@newhamhealth.nhs.uk; Federico Gonzalez - Federico.Gonzalez@newhamhealth.nhs.uk

* Corresponding author
\end{abstract}

Published: 18 January 2008

World Journal of Emergency Surgery 2008, 3:3 doi:10.1186/1749-7922-3-3

This article is available from: http://www.wjes.org/content/3/I/3

(C) 2008 Lee et al; licensee BioMed Central Ltd.

This is an Open Access article distributed under the terms of the Creative Commons Attribution License (http://creativecommons.org/licenses/by/2.0), which permits unrestricted use, distribution, and reproduction in any medium, provided the original work is properly cited.
Received: 19 September 2007

Accepted: 18 January 2008

\begin{abstract}
Background: Blue rubber bleb naevus syndrome (BRBNS), is an uncommon condition characterised by cavernous haemangiomas of skin and gastrointestinal tract. The most common complication of this syndrome is gastrointestinal bleeding. Intussusception of bowel, although a known complication, has rarely been reported.

Case presentation: We report the case of a 37-year-old man who presented with multiple intussusceptions of small bowel. He required an urgent laparotomy and bowel resections. He suffered from BRBNS. This is the first reported case of multiple synchronous intussusceptions affecting both jejunum and ileum, secondary to haemangiomas occurring in an adult with BRBNS. The underlying conditions of acute abdomen in patients with BRBNS may include intramural haemorrhage, infarction, volvulus or intussusception of bowel. Treatment options include pharmacological manipulation, bowel resection, and interventions such as sclerotherapy, angiographic embolisation, endoscopic ligation, electrocautery and laser photocoagulation for visceral lesions.
\end{abstract}

Conclusion: A high index of suspicion is required whilst dealing with acute abdomen in patients with BRBNS. Clinical trials may provide some answers as to the preference of treatment in individual cases, as the current level of evidence does not offer a clear choice of optimal treatment.

\section{Background}

Management of acute abdomen in a patient suffering from blue rubber bleb naevus syndrome can be challenging. We report a unique case of intestinal intussusception in such a patient, who was treated successfully without any complication. We discuss relevant details and provide a review of literature. Optimal management of this condi- tion remains unclear. We intend to make readers aware of potentially serious underlying conditions while dealing with acute abdomen in patients of blue rubber bleb naevus syndrome and highlight the need for optimising various treatment options. 


\section{Case presentation}

A 37-year-old male presented at Accident and Emergency department with chief complaints of colicky abdominal pain, nausea and vomiting of twelve hours' duration. The pain was generalised in nature, moderate in severity, and not associated with any aggravating or relieving factor. There was no alteration of bowel habit. His past medical history included multiple blood transfusions for 'anaemia' since childhood, Hepatitis $\mathrm{C}$ and blue rubber bleb naevus syndrome (BRBNS). The latter was diagnosed following 'bowel surgery for internal bleeding' seven years ago at a different hospital. He had been treated with endoscopy-guided argon plasma coagulation and interferon $\alpha$ therapy to induce regression of gastrointestinal haemangiomas with limited success. No other family member had suffered from a similar condition.

On admission the vital observations were stable. General examination showed several subcutaneous compressible bluish skin lesions around neck, chest and abdomen (Figure 1). Abdominal examination revealed soft and mildly distended abdomen with moderate epigastric tenderness. The bowel sounds and digital rectal examination were normal. Laboratory investigations showed haemoglobin $91 \mathrm{~g} / \mathrm{l}$, WBC $4.8 \times 10^{9} / \mathrm{l}$, platelet $144 \times 10^{9} / \mathrm{l}$. Urea, creatinine, electrolytes, liver function tests, amylase and coagulation screen were within normal limits. Plain X-ray of chest was normal. Abdominal radiograph showed distended loops of small bowel. Computed Tomography (CT) of abdomen revealed i)dilated loops of small bowel ii)'doughnut' signs, suggestive of intussusception, affecting small bowel at three different levels iii)subcapsular hepatic haemangiomas affecting segment six and iv)intramuscular haemangioma involving right quadratus lumborum muscle (Figure 2).

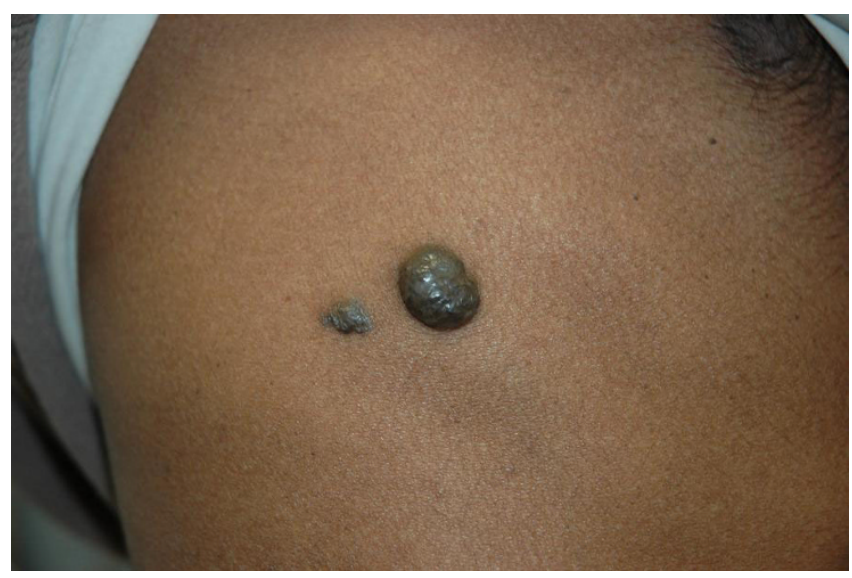

Figure I

Cutaneous haemangiomas affecting right chest wall.

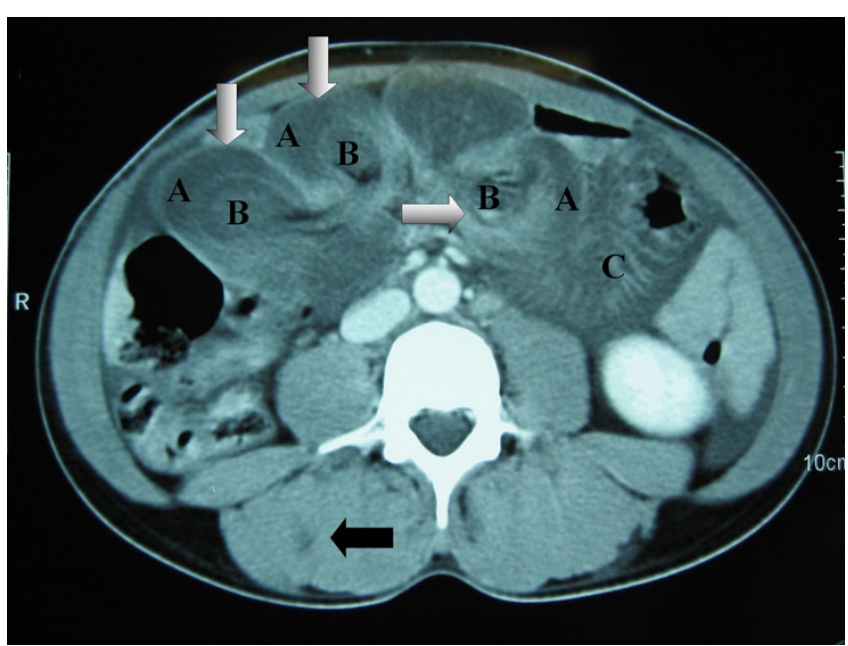

Figure 2

CT scan of abdomen showing i) multiple intussusceptions demonstrating doughnut signs (white arrows), intussusceptiens $[A]$, intussusceptum $[B]$, distended loop of small bowel $[\mathrm{C}]$ and ii) haemangioma of right quadratus lumborum muscle (dark arrow).

He underwent laparotomy that revealed three irreducible small bowel intussusceptions at the levels of proximal jejunum, mid-ileum and distal ileum. Each of the intussusception was led by a large intraluminal haemangioma. There was also a localised perforation at mid-ileal level. Resections of the intussusceptions with primary anastomosis of small bowel segments and limited right hemicolectomy were performed (Figure 3 ). The length of the remaining small bowel was $150 \mathrm{~cm}$. Histology of the specimens confirmed intussusceptions of small bowel with gangrenous changes. Multiple haemangiomas involving

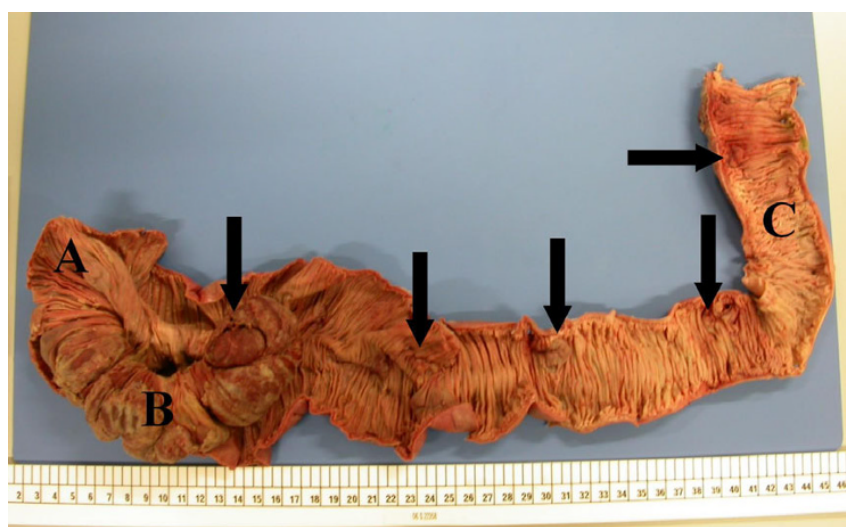

Figure 3

Specimen of limited right hemicolectomy showing terminal ileum $[\mathrm{A}]$, caecum $[\mathrm{B}]$ and ascending colon $[\mathrm{C}]$, and demonstrating multiple haemangiomas affecting mucosa and submucosa (arrows). 
serosa and submucosa were also noted. There was no feature of dysplasia or malignancy.

The postoperative course and follow-ups up to 6 months were uneventful. Further follow-ups were planned with gastroscopy, video capsule enteroscopy and colonoscopy.

\section{Discussion}

Blue rubber bleb naevus syndrome, first coined by Bean in 1958 , is an uncommon entity characterised by multiple blue naevi affecting skin and gastrointestinal organs [1]. The skin lesions appear at birth or in childhood. They are mostly located on the upper extremities and trunk [2]. In the case described, the naevi were mostly distributed around the trunk. Gastrointestinal lesions occur mostly in the small intestine and bleed easily, which results in irondeficiency anaemia [2]. Our patient had widespread lesions affecting stomach, small bowel and colon. Such lesions can give rise to intramural haemorrhage, infarction, volvulus and intussusception [3]. Intussusception of bowel in an adult without history of abdominal surgery often warrants prompt surgical intervention that usually entails bowel resection without reduction, whenever possible [4]. A high index of suspicion is warranted while dealing with acute abdomen in patients with known BRBNS or typical skin lesions that are suggestive of BRBNS. In deed, the patient reported in the case had multiple synchronous intussusceptions of small bowel affecting both jejunum and ileum, a reflection of the extent of visceral involvement. Unrestricted literature search of Medline till February 2007 showed that such a case had never been reported before. One report in the literature, closest to our case, entailed a 22-year-old man, who also had multiple intussusceptions of iluem but the jejunum was spared, making our case report unique [5].

Haemangiomatous lesions in BRBNS have also been noted to occur in the central nervous system, eye, nasopharynx, oropharynx, parotid glands, liver, spleen, pleura, lung, trachea, skeletal muscle, penis, vulva, urinary bladder, pericardium and bone [2,5-9]. There have been reported associations of BRBNS with disseminated intravascular coagulopathy, pulmonary hypertension, deep vein thrombosis, cerebellar medulloblastoma, hypernephroma, chronic lymphocytic leukaemia and angiokeratoma [10]. Differential diagnoses of BRBNS include Rendu-Osler-Weber, Klippel-Trenaunay, Maffucci, Sturge-Weber, Von- Hippel-Lindau and Cobb's Syndrome [11]. Small intestinal malignant melanoma may also present as anaemia, gastrointestinal bleed and abdominal pain. Diagnosis of such lesions can be difficult, is frequently delayed and made when complications occur [12]. Differentiation between melanoma and haemangiomatous lesions of BRBNS can be very difficult and final diagnosis often rests on histology. Only one case had been reported in the literature, citing an incidental malignant melanoma in association with progressive BRBNS [13].

BRBNS is mostly sporadic in nature [14]. However, autosomal dominance and linkage to 9p chromosome have been documented [15]. Mutation affecting tyrosine kinase (TIE2) receptor, a participant in the angiogenesis pathway, has been implicated in certain cases [16]. The patient under discussion had no family history of this syndrome, suggesting a de novo mutation as the possible underlying aetiology. Histological descriptions of naevi range from arteriovenous malformation and cavernous haemangioma to capillary telangiectasia [10]. Such lesions have not reported to be associated with malignant changes [5].

Endoscopy remains the common method of detecting gastrointestinal lesions. Abdominal radiographs may show calcifications representing well organised thrombosed visceral lesions. Barium studies may show filling defects caused by wide based sessile polyps [17]. CT and magnetic resonance imaging may aid in localisation of the lesions [18,19]. Angiography may reveal small haemangiomatous lesions and is most useful in the case of active bleeding [17].

Cosmetically compromising skin lesions can be treated by laser surgery or excision. Treatment options of gastrointestinal lesions include i) sclerotherapy, ii) angiographic embolisation, ii) endoscopic (sometimes assisted by enterotomy) ligation, electrocautery and laser photocoagulation $[20,21]$. Bowel resection is reserved for localised lesions, significant bleeding that cannot be controlled suitably by endoscopy or radiology, and for complications such as ischaemia and intussusception [21]. Role of elective radical surgical excision remains debatable $[22,23]$. Anti-angiogenic agents including corticosteroids, interferon $\alpha$ therapy and gamma globulin have been attempted $[24,25]$. However, the lesions often returned to their pre-treatment levels soon after the treatment was discontinued [24]. Our patient received interferon $\alpha$ therapy in the past without any lasting effect. None of these methods has demonstrated any convincing evidence of durable success. Choice of optimal treatment in individual cases remains unclear. Comparative trials need to be performed in order to assess the long term success prior to considering any of these therapeutic approaches as the treatment of choice. However infrequent occurrence of BRBNS could be a limiting factor in organising such trials.

\section{Conclusion}

We describe a unique case of blue rubber bleb naevus syndrome, a rare disease manifested by distinctive cutaneous and gastrointestinal haemangiomatous lesions. The com- 
monest presentation is iron deficiency anaemia. The cutaneous lesions may serve as warning signs of possible intestinal intussusception, intramural haemorrhage, infarction or volvulus in patients presenting with acute abdomen. Many therapeutic options are available, but no single therapy has yet been established as the treatment of choice. Future research involving well designed trials may shed light in this area.

\section{Abbreviations}

BRBNS - Blue rubber bleb naevus syndrome

CT - Computed tomography

\section{Competing interests}

The author(s) declare that they have no competing interests.

\section{Authors' contributions}

CL: Involved in peri-operative care including all investigations, designed the case report, collated the information, searched literature and drafted the manuscript.

DD: Involved in peri-operative care including all investigations, designed the case report, collated the information, searched literature and drafted the manuscript.

TW: Involved in peri-operative care and all investigations, assisted in providing a critical appraisal of the manuscript.

MF: Made the radiological diagnoses and assisted in preparing radiology image, advised on the format and design of the manuscript.

FG: Performed the surgery, involved in all investigations, assisted in literature search, writing and editing of the manuscript.

All authors have reviewed and approved the final manuscript.

\section{Acknowledgements}

Written consent was obtained from the patient for publication.

We would like to thank the Pathology Department, Royal London and Bart's NHS Trust, for providing the histology images.

\section{References}

I. Bean WB: Vascular Spiders and Related Lesions of the Skin. Springfield (Illinois): Charles C Thomas; 1958:178-185.

2. Oksuzoglu BC, Oksuzoglu G, Cakir U, Bayir T, Esen M: Blue rubber bleb nevus syndrome. Am J Gastroenterol 1996, 9 1:780-782.

3. Jennings $M$, Ward $P$, Maddocks JL: Blue rubber bleb naevus disease: an uncommon cause of gastrointestinal tract bleeding. Gut 1988, 29:|408-|4|2.

4. Eisen LK, Cunningham JD, Aufses AH Jr: Intussusception in adults: institutional review. J Am Coll Surg 1999, 188(4):390-395.

5. Wong SH, Lau WY: Blue rubber-bleb nevus syndrome. Dis Colon Rectum 1982, 25:37|-374.
6. Sandhu KS, Cohen H, Radin R, Buck FS: Blue rubber bleb nevus syndrome presenting with recurrences. Dig Dis Sci 1987, 32:214-219.

7. Crepeau J, Poliquin J: The blue rubber bleb nevus syndrome. J Otolaryngol 198I, 10:387-390.

8. Gallmann $T$, Boltshauser E: Blue rubber bleb nevus syndrome with CNS involvement. Klin Padiatr 1987, 199:382-384.

9. Crompton JL, Taylor D: Ocular lesions in the blue rubber bleb naevus syndrome. $\mathrm{Br}$ J Ophthalmol I98I, 65:|33-I37.

10. Gabikian P, Clatterbuck RE, Gailloud P, Rigamonti D: Developmental venous anomalies and sinus pericranii in the blue rubberbleb nevus syndrome. Case report. Case report J Neurosurg 2003, 99(2):409-4II.

11. Rodrigues D, Bourroul ML, Ferrer AP, Monteiro Neto H, Goncalves ME, Cardoso SR: Blue rubber bleb nevus syndrome. Rev Hosp Clin Fac Med Sao Paulo 2000, 55:29-34.

12. Hao XS, Li Q, Chen H: Small bowel metastases of malignant melanoma: palliative effect of surgical resection. Jpn J Clin Oncol 1999, 29(9):442-444.

13. Kinner S, Herborn CU, Kroeger K: Simultaneous manifestation of blue-rubber-bleb-nevus-syndrome and malignant melanoma. Vasa 2006, 35(4):239-24I.

14. Munkvad M: Blue rubber bleb nevus syndrome. Dermatologica 1983, 167:307-309.

15. Gallione CJ, Pasyk KA, Boon LM, Lennon F, Johnson DW, Helmbold EA, Markel DS, Vikkula M, Mulliken JB, Warman ML: A gene for familial venous malformations maps to chromosome $9 p$ in a second large kindred. J Med Genet 1995, 32:197-199.

16. Vikkula M, Boon LM, Carraway KL 3rd, Calvert JT, Diamonti AJ, Goumnerov B, Pasyk KA, Marchuk DA, Warman ML, Cantley LC, Mulliken JB, Olsen BR: Vascular dysmorphogenesis caused by an activating mutation in the receptor tyrosine kinase TIE2. Cell 1996, 87: II53-II 55.

17. Baker AL, Kahn PC, Binder SC, Patterson JF: Gastrointestinal bleeding due to blue rubber bleb nevus syndrome syndrome. A case diagnosed by angiography. Gastroenterology 1971, 61:530-534.

18. Tyrrel RT, Baumgartner BR, Montemayor KA: Blue rubber bleb nevus syndrome: $C T$ diagnosis of intussusception. Am J Roentgenol 1990, I54(I): 105-106.

19. Jorizzo JR, Amparo EG: MR imaging of blue rubber bleb nevus syndrome. J Comput Assist Tomogr 1986, 10:686-688.

20. Morris L, Lynch PM, Gleason WA Jr, Schauder C, Pinkel D, Duvic M: Blue rubber bleb nevus syndrome: laser photocoagulation of colonic hemangiomas in a child with microcytic anemia. Pediatr Dermatol 1992, 9:91-94.

21. Abrahamson J, Shandling B: Intestinal hemangiomata in childhood and a syndrome for diagnosis: a collective review. J Pediatr Surg 1973, 8:487-495.

22. Fishman SJ, Smithers CJ, Folkman J, Lund DP, Burrows PE, Mulliken JB, Fox VL: Blue rubber bleb nevus syndrome: surgical eradication of gastrointestinal bleeding. Ann Surg 2005, 24I:523-528.

23. Watanabe Y, Sato M, Tokui K, Yukumi S, Koga S, Nezu K, Matsui H, Murakami $\mathrm{H}$, Kawachi K: Multiendoscope-assisted treatment for blue rubber bleb nevus syndrome. Surg Endosc 2000, I 4:595.

24. Boente MD, Cordisco MR, Frontini MD, Asial RA: Blue rubber bleb nevus (Bean syndrome): evolution of four cases and clinical response to pharmacologic agents. Pediatr Dermatol 1999 , 16:222-227.

25. Aihara M, Konuma Y, Okawa K, Komai R, Kudo I, Morioka R, Kariya K, Takami H, Sadwada Y, Munakata A, Yoshida Y: Blue rubber bleb nevus syndrome with disseminated intravascular coagulation and thrombocytopenia: successful treatment with highdose intravenous gammaglobulin. Tohoku J Exp Med I99|, 163:III-II7. 